\title{
Working with Individuals Who Provide Nursing Care to Educate Older Adults about Foodborne Illness Prevention: The Food Safety Because You Care! Intervention
}

\author{
Kelly C. Wohlgenant, ${ }^{1}$ Sandria L. Godwin, ${ }^{2}$ Sheryl C. Cates, ${ }^{1}$ and Richard Stone ${ }^{2}$ \\ ${ }^{1}$ RTI International, 3040 Cornwallis Road, Research Triangle Park, NC 27709, USA \\ ${ }^{2}$ Department of Family and Consumer Sciences, Tennessee State University, 3500 John A. Merritt Boulevard, \\ Nashville, TN 37209, USA \\ Correspondence should be addressed to Sheryl C. Cates; scc@rti.org
}

Received 28 October 2014; Accepted 14 January 2015

Academic Editor: Sumantra Ray

Copyright (C) 2015 Kelly C. Wohlgenant et al. This is an open access article distributed under the Creative Commons Attribution License, which permits unrestricted use, distribution, and reproduction in any medium, provided the original work is properly cited.

Older adults are more susceptible to foodborne infections than younger adults and many older adults do not follow recommended food safety practices. This study implemented the Food Safety Because You Care! program with 88 individuals in the United States who provide nursing care to older adult patients and subsequently surveyed them. The majority of respondents had favorable opinions of the program. Following program exposure, many of the respondents advised their older adult patients about food safety. The findings from this study suggest that the program is a useful tool that can assist those who provide nursing care as they interact with their older patients and lead them to positively influence older adults' food safety practices. However, more research is needed to examine changes in providers' behaviors as a result of program exposure and the accompanying effect on older adults' food safety practices.

\section{Introduction}

To build healthy eating patterns, the 2010 Dietary Guidelines for Americans recommends that all people follow food safety recommendations when preparing and eating foods to reduce the risk of foodborne illnesses [1]. Older adults are at a greater risk for developing serious complications from foodborne infections compared with younger adults [2-5]. Factors such as decreased stomach acid production, intestinal motility, malnutrition, immobility, chronic diseases, living in a nursing home environment, and increased use of antibiotics cause older adults to be more susceptible to foodborne infections $[5,6]$. This is evidenced by a recent multistate outbreak of Listeria monocytogenes that most likely originated from contaminated cantaloupes. According to the Centers for Disease Control and Prevention, among the 72 ill persons affected by the outbreak most were aged 60 or older or had weakened immune systems [7].

Although foodborne illnesses are an imminent health concern for older adults, experts have identified practices that can help mitigate the risk of acquiring foodborne illnesses [8-10]. These practices include avoiding foods that are more likely to be contaminated with pathogens such as raw or undercooked eggs; raw or undercooked meat, poultry, or seafood; hot dogs and deli meats that have not been reheated to steaming hot; soft cheeses made from unpasteurized milk; raw sprouts; and unpasteurized milk and juices; using an appliance thermometer to ensure the refrigerator's ambient temperature is $40^{\circ} \mathrm{F}$ or less; using a food thermometer to check the internal temperature of meat and poultry dishes; refrigerating food promptly; and other practices. However, research suggests that many older adults may not be following recommended food safety practices [11-14].

A nationally representative survey of older adults [11] and a study conducted by Boone and colleagues [12] revealed that seniors would prefer to learn about food safety from their health care providers. Focus groups with several types of health care professionals found that nurses were receptive to providing food safety information to their senior patients [15]. A few resources have been developed to communicate 
TABLE 1: Booklet sections.

\begin{tabular}{|c|c|}
\hline Section & Topics covered \\
\hline (1) Learn about Foodborne Illness & $\begin{array}{l}\text { Reasons older adults are susceptible to foodborne infections, symptoms } \\
\text { associated with foodborne illness, and caring for someone with foodborne } \\
\text { illness }\end{array}$ \\
\hline (2) Foods Seniors Outgrow & Foods older adults should avoid eating to prevent foodborne illness \\
\hline (3) Food Storage 101 & Recommended storage times for foods and how to safely store leftovers \\
\hline (4) The Right Tools for a Spotless Kitchen & $\begin{array}{l}\text { Tools needed to maintain a sanitary kitchen and tips such as using an } \\
\text { appliance thermometer to ensure the refrigerator's temperature is } 40^{\circ} \mathrm{F} \text { or } \\
\text { below }\end{array}$ \\
\hline (5) Keeping Food Clean and Safe to Eat & $\begin{array}{l}\text { Safe hand washing, sanitation, and food hygiene practices (e.g., washing } \\
\text { produce or methods for preventing cross contamination) }\end{array}$ \\
\hline (6) How to Get Rid of Those Hidden Germs & Kitchen sanitation \\
\hline (7) Safe Cooking and Cooling Temperatures & $\begin{array}{l}\text { Recommended lethality temperatures for cooking raw meats and how to } \\
\text { safely thaw food }\end{array}$ \\
\hline (8) What to Do If a Food Product Is Recalled & Responding to food recalls and identifying signs of product tampering \\
\hline
\end{tabular}

foodborne illness management and food safety information to health care professionals $[16,17]$. However, to our knowledge, none have specifically been tailored to nurse-older adult patient communications about food safety.

The aim of this study was to implement the Food Safety Because You Care! Intervention, a program developed for those who provide nursing care for older adult patients and to assess participants' response to the program. The intervention was an educational booklet developed by Tennessee State University that provided information tailored to nurse-older adult patient communications about foodborne illnesses and how to prevent them. This study examined participants' opinions of the booklet and whether the booklet motivated them to share the booklet with others or provide food safety information to their older adult patients.

\section{Materials and Methods}

2.1. Intervention. The Food Safety Because You Care! Intervention is a 47-page educational booklet that includes food safety tips and quizzes intended for older adults and those who care for them. The food safety tips are based on expert recommendations for preventing foodborne illness and are in line with the USDA's and FDA's food safety recommendations. Table 1 describes each section of the food safety booklet. The booklet uses a large font size, large colorful graphics, and nontechnical language so that older adults with failing eyesight or decreased cognitive functioning can easily read and understand it. The booklet is currently accessible online at http://fnic.nal.usda.gov/nal_web/fsrio/fseddb/fseddbsearchdetails.php?id=1922.

2.2. Survey Design and Participant Recruitment. To assess response to the intervention, we conducted a post-only retrospective survey without a control or comparison group. Using convenience sampling, we recruited study participants from June to December 2011 using the following methods: (1) placing advertisements in the American Nurses Association e-newsletters, (2) posting study recruitment announcements on Craigslist, and (3) using Zoomerang's Web panel of nurses. Additionally, we disseminated booklets and recruited individuals for the study at local conferences, including the Tennessee Nurse's Association and Tennessee Association of Student Nurses Joint Convention and the Tennessee Public Health Association's Annual Education Conference. Study participants were required to care for patients aged 60 or older and be a nurse practitioner, registered nurse, licensed practical nurse, or certified nursing assistant.

2.3. Study Procedures and Questionnaire. One to three weeks after the booklets were disseminated, we administered the survey via the participant's preferred method: Web or traditional pen-and-paper method. Participants who received hard copy booklets either in person at the conferences or by request in the mail were sent a reminder to read the booklet 1 week before we fielded the paper or Web-based survey. Other participants who expressed interest in our study and were provided digital copies of the booklets via e-mail were told they would be contacted again about a week after receiving the booklet and provided with the survey Web link. The Webbased survey was hosted by SurveyMonkey (Palo Alto, CA). To increase the response rate, all participants were sent reminders to complete the survey 1 week after it was fielded.

The survey collected information on participants' opinions of the booklet, current food safety knowledge, and any changes made following exposure to the intervention. All study procedures were approved by RTI International's Institutional Review Board, and all study participants were financially compensated for completing the survey.

\section{Results}

3.1. Study Population Characteristics. A total of 88 individuals from across the United States completed the survey. For $77 \%$ of the respondents, more than $50 \%$ of their patients were aged 60 or older. Fifty-five percent of the respondents were registered nurses, and $43 \%$ of the respondents specialized in geriatrics. The majority of the respondents worked in long-term 
TABLE 2: Respondents' opinions of the booklet $(n=88)$.

\begin{tabular}{|c|c|c|c|c|c|c|}
\hline Statement & $\%$ strongly agree & $\%$ agree & $\begin{array}{l}\% \text { neither agree } \\
\text { nor disagree }\end{array}$ & $\%$ disagree & $\begin{array}{l}\% \text { strongly } \\
\text { disagree }\end{array}$ & $\begin{array}{l}\% \text { do not } \\
\text { remember/no } \\
\text { answer }\end{array}$ \\
\hline $\begin{array}{l}\text { After reading the booklet I now } \\
\text { feel better prepared to advise } \\
\text { older adults and/or their } \\
\text { caregivers to safely prepare food. }\end{array}$ & 54.6 & 36.4 & 4.6 & 1.1 & 1.1 & 2.3 \\
\hline $\begin{array}{l}\text { The information in this booklet } \\
\text { was easy to understand. }\end{array}$ & 60.2 & 29.6 & 3.4 & 0 & 1.1 & 5.7 \\
\hline $\begin{array}{l}\text { Reading this booklet made me } \\
\text { more aware of food safety. }\end{array}$ & 56.8 & 35.2 & 2.3 & 2.3 & 2.3 & 1.1 \\
\hline $\begin{array}{l}\text { I learned at least one new thing } \\
\text { regarding food safety after } \\
\text { reading the booklet. }\end{array}$ & 58.0 & 29.6 & 6.8 & 1.1 & 1.1 & 3.4 \\
\hline $\begin{array}{l}\text { Reading this booklet has shown } \\
\text { me that I do not know enough } \\
\text { about properly preparing food } \\
\text { for older adults. }\end{array}$ & 21.6 & 33.0 & 23.9 & 15.9 & 4.6 & 1.1 \\
\hline $\begin{array}{l}\text { There was too much information } \\
\text { to read. }\end{array}$ & 5.7 & 18.2 & 22.7 & 34.1 & 17.1 & 2.3 \\
\hline $\begin{array}{l}\text { I thought the information was } \\
\text { interesting. }\end{array}$ & 47.7 & 43.2 & 5.7 & 0 & 1.1 & 2.3 \\
\hline $\begin{array}{l}\text { The booklet was tailored to older } \\
\text { adults. }\end{array}$ & 23.9 & 40.9 & 20.5 & 11.4 & 2.3 & 1.1 \\
\hline $\begin{array}{l}\text { I found the information to be } \\
\text { credible. }\end{array}$ & 48.9 & 42.1 & 4.6 & 0 & 2.3 & 2.3 \\
\hline $\begin{array}{l}\text { Adults aged } 60 \text { or older are at an } \\
\text { increased risk of getting food } \\
\text { poisoning or foodborne illness. }\end{array}$ & 56.8 & 29.6 & 6.8 & 3.4 & 2.3 & 1.1 \\
\hline
\end{tabular}

care/rehabilitation facilities (27\%) or hospital settings (26\%); thus their patients required ongoing nursing care, whereas the patients of respondents who worked in other settings (e.g., doctor's offices) were not receiving ongoing nursing care.

3.2. Opinions of the Booklet. Table 2 describes respondents' impressions of the booklet. Seventy-three percent of the respondents found it to be very informative, and $68 \%$ found it to be very useful. Seventy-four percent reported that they did all or most of the quizzes in the booklet. Ninety percent of respondents agreed that the information provided in the booklet was easy to understand, interesting, and credible. Over $90 \%$ of respondents agreed that after reading the booklet they were better prepared to advise older adults and/or their caregivers to safely prepare food and that they were more aware of food safety. More than half of respondents agreed that the booklet showed them that they did not know enough about properly preparing food for older adults, and $24 \%$ of respondents agreed that the booklet was too lengthy.

Respondents indicated that they would be likely to refer back to the booklet and share it with others. Forty-four percent of respondents reported that they filed the booklet or put it somewhere so that they could refer to it again in the future, $39 \%$ shared it with a colleague, and $24 \%$ shared it with an older adult and/or their caregiver. Nearly two-thirds of respondents reported that they would be very likely to share the booklet.

3.3. Current Practices. Ninety-one percent of respondents $(n=80)$ provided food safety information to their older adult patients before participating in the study. Of those respondents, $40 \%$ reported that they frequently or very frequently provide food safety information to their older adult patients. The most common topics were foods to avoid eating and recommended practices for handling and preparing food safely at home.

3.4. Reported Changes in Behavior following Exposure. After reading the booklet, $57 \%$ of respondents reported that they advised their patients not to eat certain foods because of concerns about food safety, and $57 \%$ of respondents reported that they gave their patients recommendations on how to safely store, handle, or prepare food at home. Respondents who reported providing these recommendations to their patients were then asked via unaided, open-ended questions to specifically describe the dietary and/or food storage/handling recommendations they gave their patients. Responses to the opened-ended questions are provided in Table 3.

Among those who responded to the follow-up question and described dietary recommendations they had given to their patients $(n=41)$ (nine respondents skipped the 
TABLE 3: Respondents' recommendations to their patients as a result of reading the booklet.

\begin{tabular}{|c|c|}
\hline What foods have you advised your patients aged 60 or older not to eat based on what you learned in the booklet? $(n=41)^{*}$ & $\%$ \\
\hline Foods containing raw or undercooked eggs & 26.8 \\
\hline Raw or undercooked meat or poultry & 24.4 \\
\hline Mold-ripened, blue veined, or soft cheeses & 19.5 \\
\hline Deli meats eaten without reheating & 14.6 \\
\hline Food stored at improper temperatures & 14.6 \\
\hline Hot dogs eaten without reheating & 7.3 \\
\hline Raw or undercooked fish or seafood & 9.8 \\
\hline Raw, unpasteurized milk & 9.8 \\
\hline Raw sprouts & 7.3 \\
\hline Unpasteurized juices, cider, or honey & 2.4 \\
\hline Expired food & 4.9 \\
\hline Food stored in can that is dented, leaking, or swollen & 4.9 \\
\hline Describe recommendations you have given to your patients and/or their caregivers since reading the booklet $(n=41)^{*}$ & $\%$ \\
\hline Proper storage time for refrigerated foods & 31.7 \\
\hline Other storage practices, nec & 29.3 \\
\hline Proper kitchen hygiene & 14.6 \\
\hline Refrigerate perishable food promptly (not more than 2 hours at room temperature) & 12.3 \\
\hline Other food-handling practices, nec & 12.2 \\
\hline Check refrigerator temperature & 9.8 \\
\hline Use food thermometer for cooking meat, poultry, seafood, and eggs & 9.8 \\
\hline Other cooking practices, nec & 7.3 \\
\hline Proper personal hygiene (hand washing) & 7.3 \\
\hline Washing produce & 7.3 \\
\hline Procedures for preventing cross contamination & 4.9 \\
\hline Reheating deli meats & 4.9 \\
\hline
\end{tabular}

${ }^{*}$ Nine respondents skipped question or did not provide a legible response. nec $=$ not elsewhere classified.

question or did not provide a legible response), respondents recommended that their older adult patients avoid eating the following foods as indicated in the booklet: foods containing raw or undercooked eggs (27\%); raw or undercooked meat or poultry (24\%); and mold-ripened, blue veined, or soft cheeses (20\%). Among respondents who described recommendations they had given their patients for safe food storage, handling, or preparation $(n=41)$ (nine respondents skipped the question or did not provide a legible response), almost a third recommended proper storage times for refrigerator foods or recommended other storage practices not already specified, including storing pantry items in closed containers, setting the freezer at the proper temperature, or storing frozen foods for the proper amount of time.

The booklet recommends that older adults use an appliance thermometer to monitor their refrigerator's temperature and a food thermometer to check meat and poultry dishes for doneness. After reading the booklet, $40 \%$ of respondents reported that they advised patients aged 60 or older and/or their caregivers to put appliance thermometers in their refrigerator, and $56 \%$ of respondents advised their patients to use a food thermometer. The booklet also recommends that older adults cook eggs until they are firm. After reading the booklet,
$48 \%$ of respondents reported that they advised their patients to change the way they prepare fried eggs.

\section{Discussion/Conclusions}

The nurses and other care providers surveyed had favorable impressions of the booklet and believed that it better prepared them to advise older adults and/or their caregivers on recommended food safety practices. Based on the results of the survey, the booklet appeared to motivate respondents to educate older adult patients about food safety. Education consisted of advising older adult patients not to eat certain "risky" foods or advising patients on how to safely store, handle, or prepare food when cooking at home. The booklet also led some respondents to recommend that patients use appliance thermometers to ensure that perishable foods are stored at $40^{\circ} \mathrm{F}$ or below or recommend that patients use food thermometers to check the internal temperature of meat and poultry dishes for doneness.

Overall the program appeared to increase respondents' comfort level with making food safety recommendations to patients. This is important because, as discussed by Kendall and colleagues [8], older adults rely on health care providers 
as a trusted and desired source for receiving health information, and studies suggest that older adults would prefer to receive food safety information from their health care provider $[11,12]$. Unique features of this booklet are that the information is presented in an easy-to-use and interactive format that was interesting for nurses/care providers to read but could also be shared with patients who may have decreased eyesight or cognitive functioning. It offered suggestions for how older adults might change some of their behaviors to help prevent foodborne illness. Thus, the design of the booklet followed several of Higgins and Barkley [18] recommendations for promoting behavior change among older adults. These recommendations include keep program content practical and relevant and to structure the program to increase retention by using familiar terminology and simplifying concepts.

This study had some limitations. First, the sample was not probability based and a relatively small number of individuals who provide nursing care to older adults were surveyed; thus the results of these individuals cannot be generalizable to the US population. Second, the study was retrospective and did not include a counterfactual condition in order to establish causality of program impacts. Additional research is needed to examine whether the behaviors of nurses and those who provide nursing care are changed over the long term as a result of program exposure and whether the information provided leads older adult patients to improve their food safety practices.

In summary, this study found that respondents had favorable opinions of the Food Safety Because You Care! program and were motivated to share food safety information with their older adult patients. This suggests that the program may serve as a useful tool in helping older adults improve their food safety practices. However, more research is needed to examine changes in older adults' behaviors as a result of the program.

\section{Conflict of Interests}

The authors declare that there is no conflict of interests regarding the publication of this paper.

\section{Acknowledgment}

This work was partially funded through a grant from the National Integrated Food Safety Initiative of the US Department of Agriculture's Cooperative State Research, Education and Extension Service (Grant no. 2009-51110-20145).

\section{References}

[1] U.S. Department of Agriculture and U.S. Department of Health and Human Services, Dietary guidelines for Americans, 2010, http://www.health.gov/dietaryguidelines/dga2010/DietaryGuidelines2010.pdf.

[2] J. C. Buzby, "Older adults at risk of complications from microbial foodborne illness," Food Review, vol. 25, no. 2, pp. 30-35, 2002.
[3] C. P. Gerba, J. B. Rose, and C. N. Haas, "Sensitive populations: who is at the greatest risk?" International Journal of Food Microbiology, vol. 30, no. 1-2, pp. 113-123, 1996.

[4] K. C. Klontz, W. H. Adler, and M. Potter, "Age-dependent resistance factors in the pathogenesis of foodborne infectious disease," Aging Clinical and Experimental Research, vol. 9, no. 5, pp. 320-326, 1997.

[5] J. L. Smith, "Review: foodborne illness in the elderly," Journal of Food Protection, vol. 61, no. 9, pp. 1229-1239, 1998.

[6] P. A. Kendall, V. V. Hillers, and L. C. Medeiros, "Food safety guidance for older adults," Clinical Infectious Diseases, vol. 42, no. 9, pp. 1298-1304, 2006.

[7] Centers for Disease Control and Prevention, Investigation Update: Multistate Outbreak of Listeriosis Linked to Whole Cantaloupes from Jensen Farms, Colorado, 2011, http://www .cdc.gov/listeria/outbreaks/cantaloupes-jensen-farms/092711/ index.html.

[8] P. Kendall, L. C. Medeiros, V. Hillers, G. Chen, and S. Dimascola, "Food handling behaviors of special importance for pregnant women, infants and young children, the elderly, and immune-compromised people," Journal of the American Dietetic Association, vol. 103, no. 12, pp. 1646-1649, 2003.

[9] P. K. Yen, "Preventing harm form food-borne illness," Geriatric Nursing, vol. 24, no. 6, pp. 376-377, 2003.

[10] Food and Drug Administration [FDA] and U.S. Department of Agriculture [USDA], "To Your Health! Food Safety for Seniors," http://www.fda.gov/downloads/Food/ResourcesForYou/Consumers/Seniors/UCM182784.pdf.

[11] S. C. Cates, K. M. Kosa, S. Karns et al., "Food safety knowledge and practices among older adults: identifying causes and solutions for risky behaviors," Journal of Nutrition for the Elderly, vol. 28, no. 2, pp. 112-126, 2009.

[12] K. Boone, K. Penner, J. C. Gordon, V. Remig, L. Harvey, and T. Clark, "Common themes of safe food-handling behavior among mature adults," Food Protection Trends, vol. 25, no. 9, pp. 706711, 2005.

[13] M. A. Gettings and N. E. Kiernan, "Practices and perceptions of food safety among seniors who prepare meals at home," Journal of Nutrition Education and Behavior, vol. 33, no. 3, pp. 148-154, 2001.

[14] J. Lenhart, P. Kendall, L. Medeiros, J. Doorn, M. Schroeder, and J. Sofos, "Consumer assessment of safety and date labeling statements on ready-to-eat meat and poultry products designed to minimize risk of listeriosis," Journal of Food Protection, vol. 71, no. 1, pp. 70-76, 2008.

[15] K. C. Wohlgenant, S. C. Cates, S. L. Godwin, and L. SpellerHenderson, "The role of healthcare providers and caregivers in educating older adults about foodborne illness prevention," Educational Gerontology, vol. 38, no. 11, pp. 753-762, 2012.

[16] The Ohio State University, "Food Safety for High Risk Populations," 2012, http://www.csrees.usda.gov/funding/integrated/ pdfs/food_safety.pdf.

[17] Centers for Disease Control and Prevention, Diagnosis and Management of Foodborne Illnesses: A Primer for Physicians, 2001, http://www.cdc.gov/mmwr/preview/mmwrhtml/rr5002al .htm.

[18] M. Higgins and M. Barkley, "Tailoring nutrition education intervention programs to meet needs and interests of older adults," Journal of Nutrition for the Elderly, vol. 23, no. 1, pp. 5979, 2003. 

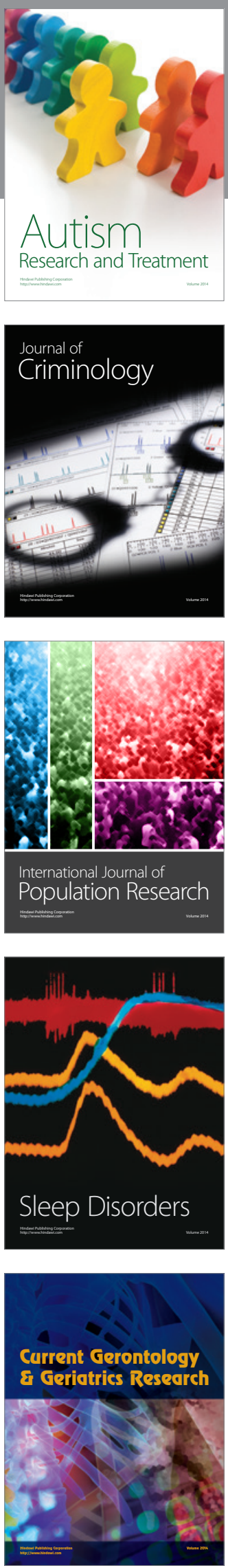
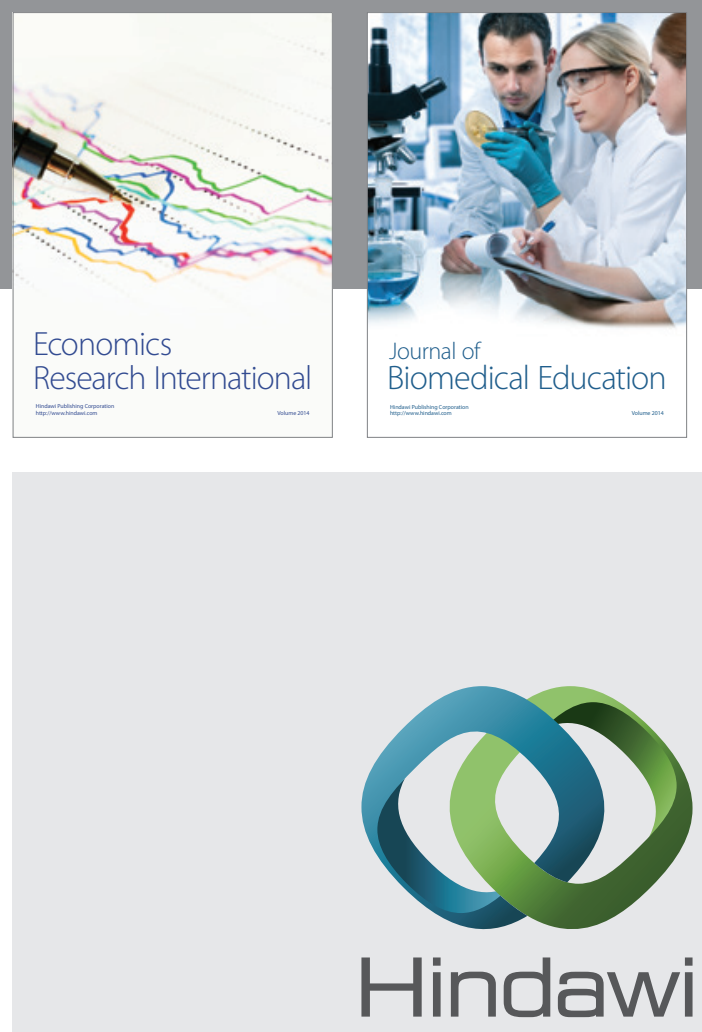

Submit your manuscripts at

http://www.hindawi.com
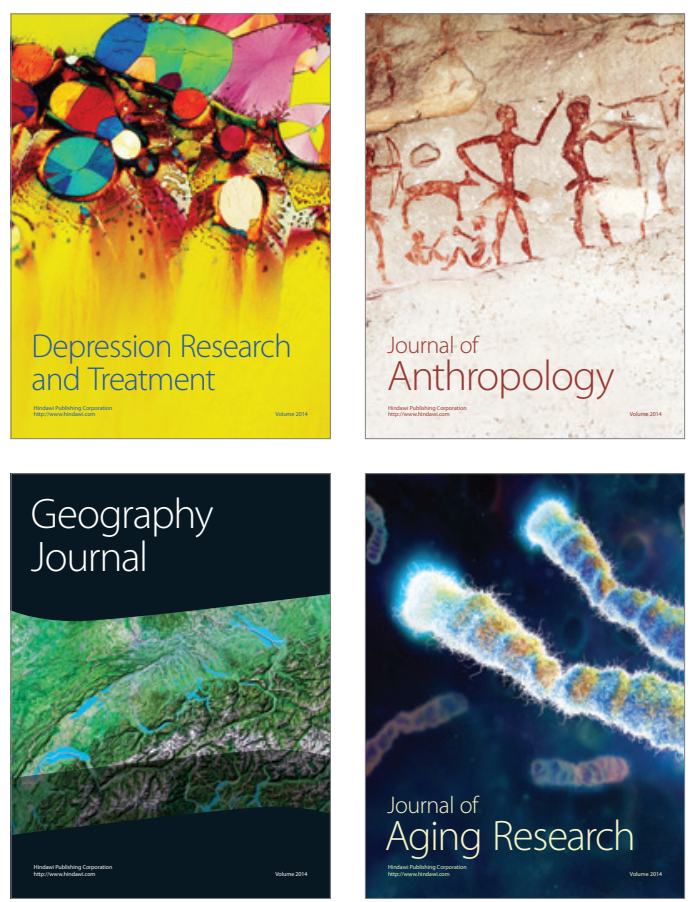
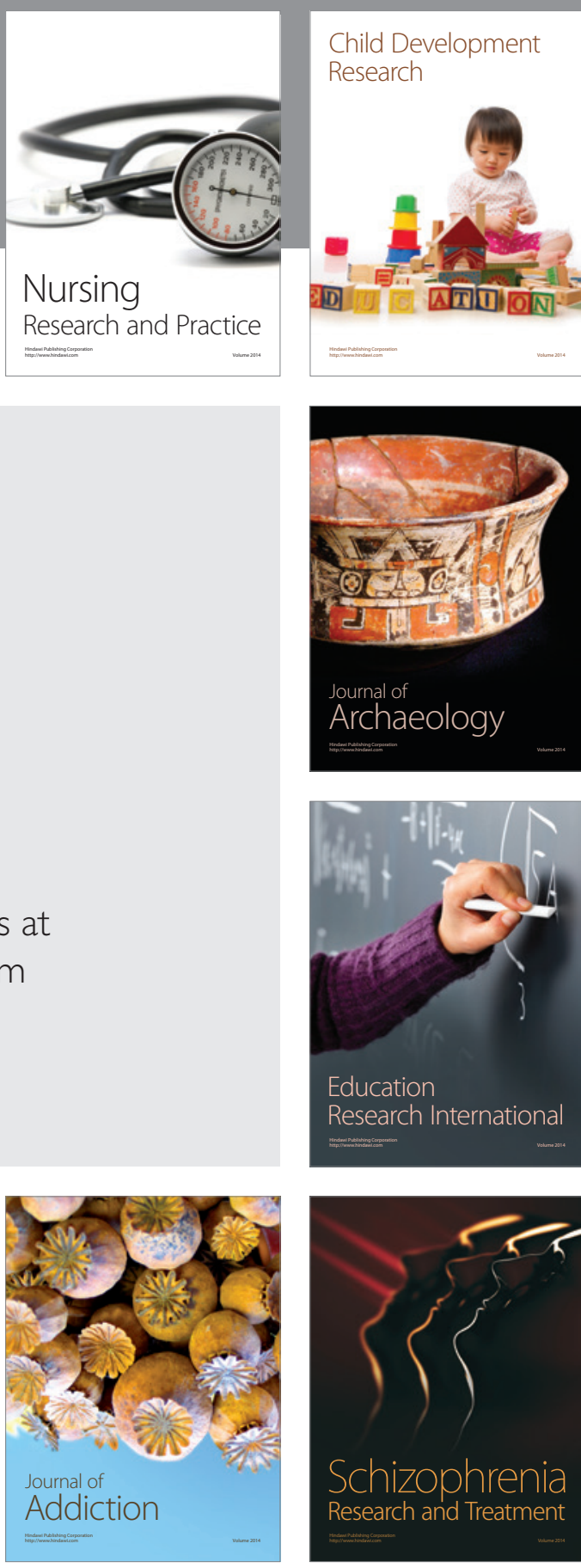

(D)
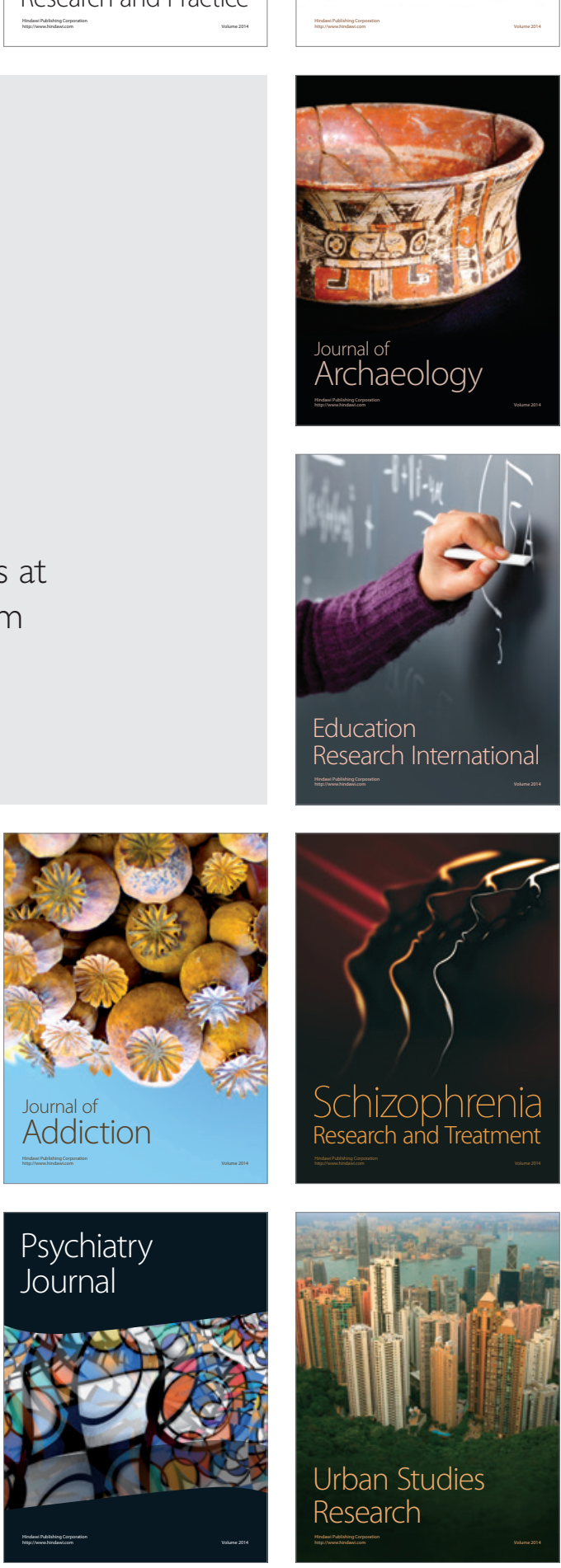